\title{
'IT'S TOUGH BEING GAY'. GAY, LESBIAN AND BISEXUAL STUDENTS' EXPERIENCES OF BEING 'AT HOME' IN SOUTH AFRICAN UNIVERSITY RESIDENCE LIFE
}

\author{
C. Munyuki* \\ e-mail: chipo4m@gmail.com
}

\section{D. Vincent*}

e-mail: I.vincent@ru.ac.za

*Political and International Studies

Rhodes University

Grahamstown, South Africa

\section{ABSTRACT}

In the post-apartheid era, a variety of commentators invoked the idea of making university campuses a 'home for all' so as to depict a vision of what transformed, inclusive higher education institutional cultures, might look like. In this article, we discuss the experiences of students who self-identified as gay, lesbian or bisexual of being 'at home' in university residence life on a largely residential South African campus. Drawing from many different disciplines, including anthropology, history, philosophy, geography, psychology, architecture and sociology, we distil the essential features of 'at-homeness' as incorporating comfort, privacy, security, acceptance, companionship, recognition and community - all of which are central to human flourishing. We find that while some participants reported being afforded the advantages of feeling at home in university residence life, others are routinely denied many of the essential comforts associated with being 'at home' that heterosexual students have the privilege of taking for granted as a component of their experience of university residence life.

Key words: LGB students; higher education; South Africa; transformation; institutional cultures; university residence life; home

\section{INTRODUCTION}

A wide body of research finds that universities are frequently experienced as unsafe and unaccepting environments by LGBTI students (Reed et al. 2010; Yost and Gilmore 2011; Woodford, Krentzman and Gattis 2012; Tetreault et al. 2013), that homophobia is endemic in institutions of higher education (Ellis 2008, 6; Kane 2013, 829) and that its effects on the wellbeing of LGBTI students are severe and far-reaching (Rhoads 1995, 73). Incidents of harassment range in severity from verbal abuse to discrimination and physical violence 
(Westefeld et al. 2001; Jenkins, Lambert and Baker 2009; Francis and Msibi 2011; Msibi 2013). D’Augelli $(1989,133)$ found that almost half of the students who participated in a survey on their experiences of harassment and discrimination chose to conceal their sexuality, pretending to be heterosexual so as to avoid victimisation, or dissociated from known gay and lesbian peers (see also Tetreault et al. 2013, 949).

Almost two decades ago, Evans and D’Augelli $(1996,222)$ challenged institutions of higher education to fulfil their moral responsibility of providing LGBTI students with safe environments in which they have an opportunity to flourish. Similarly, Engstrom and Sedlacek (1997, 575) argued for the unacknowledged privileges routinely accorded to heterosexual students to be confronted. More recent work (Jenkins, Lambert and Baker 2009; Francis and Msibi 2011; Msibi 2013) suggests that the challenges identified in this earlier body of work remain unmet and that LGBTI students continue to encounter campus climates that are hostile to them because of their sexual orientation (Woodford, Krentzman and Gattis 2012; Beemyn and Rankin 2011; Msibi 2013).

While there exists a large body of literature on the experiences of LGBTI students at tertiary education institutions, very little of this work has been conducted in South Africa. Most of the existing research conducted at South African institutions of higher education has taken the form of surveys and questionnaires (Arndt 2004; Arndt and De Bruin 2006) that focus on attitudes towards LGBTI students. This work finds that campuses are microcosmic in the wider social context which, notwithstanding the protection of the Constitution, sees widespread discrimination against LGBTI people on a daily basis (Richardson 2006; Msibi 2013).

Following the demise of apartheid, the newly elected democratic government faced the challenge of overhauling unjust institutions and practices, across society that had been inherited from the past. The need to transform the country's higher education institutions (HEIs) is one instance of this wider project of transforming the practices, cultures and structures of apartheid. Government's vision for a transformed South African higher education system, captured in the Education White Paper 3 (Department of Education 1997), calls for the promotion of 'equity of access and fair chances of success' for all those wanting to realise their potential through higher education. It also calls for the eradication of all forms of unfair discrimination, redress for past inequalities and the inculcation of a democratic ethos, a culture of human rights, practices conducive to critical discourse and creative thinking, tolerance, and a common commitment to a humane, non-racist, non-sexist social order.

However, existing research notes that while many HEIs have made progress with respect to changing their demographic make-up, inequities persist and these institutions still have a 
long way to go with regard to constituting themselves as environments in which all are equally able to flourish and reach their potential (see Department of Education 2008; Soudien 2010; Govinder, Zondo and Makgoba 2013). It has also been noted that to date, higher education transformation in South Africa has tended to be focused on 'race' and, to a lesser extent on gender, while little attention has been paid to the question of sexual minorities and how cultures of heteronormativity and homophobia serve to perpetuate exclusion on campuses (Donaldson 2015, 130; Department of Education 2008, 46).

As has been frequently pointed out (see for example D’Augelli 1989; Nelson and Baker 1990; Engstrom and Sedlacek 1997, 574; Waldo 1998, 769), creating inclusive campus environments has to transcend formal policy to permeate day-to-day practices, values and assumptions. The idea of making university campuses 'homes for all' has been invoked by a variety of commentators (see for example Thaver 2006; Vice 2015). They seek to depict this deeper sense of what transformed, inclusive higher education institutional cultures might look like and to acknowledge also that there are aspects of institutional cultures that create discomfort for some.

'Home' has been theorised as incorporating social networks, identity, privacy, continuity, self-expression, warmth, and feeling welcome (see Manzo 2003; Easthope 2004; Hauge 2007; Moore 2007; Jacobson 2009). It thus speaks to a range of significant human needs essential for human flourishing. Rasmussen and Den Uyl (2005 in Younkins 2008, 267-268) argue that human flourishing is not only concerned with feelings and experiences of subjective well-being. Human flourishing requires a life with other people in a social context and the scholars identify friendship as one of the components of human flourishing (Younkins 2008, 267-268). However, as Thaver has pointed out $(2006,17)$, not everyone has the privilege of experiencing home in this way. The idealised conception of home as a place of nurturing, stability and permanence that comes from caring relationships, support and mutual recognition (Mallet 2004, 71; Bowlby, Gregory and McKie 1997, 344) has been criticised by those who remind us that for many, homes are places for the enactment of patriarchal hierarchies, oppressions, and violence (George 1996, 9; Kaplan 1987, 194). It is not uncommon for those who do not share the characteristics that are valued by other occupants - who are unable to, or choose not to, conform to conventional norms - to be symbolically and often literally excluded from the home. These excluded members may remain visible in the home however - often hyper-visible - and a perceived threat to the way of life of the other occupants (Wardhaugh 1999, 97). Homes are a delineation of boundaries and this selective inclusivity and strong sense of identity that necessarily inheres in the concept means that home can also be a place of fear, abuse, isolation 
and loneliness for those who do not, for some reason, fit in with the prescribed mores delineating the criteria for inclusion.

The fraught idea of 'the home' can be contrasted with the notion of feeling 'at home'. Said (1983) has pointed out that there is a distinction between the physical place as home and the social relations that produce that state of being 'at home'. It is quite possible to be 'home' and not to feel 'at home' - a dyad which we explore in this article. For Thaver $(2006,18)$ the distinction has to do, critically, with social relations:

The critical factor here is that it is in social relations with other social actors in a given place that mutual assurances, fitness, belonging, etc. obtain and through which the feeling of being 'at home' is ultimately generated. The question is never: Do you feel at home? It is rather: Where, and with whom, doing what, and to what end, do you feel comfortable enough to be able to say, 'I feel "at home" or "in place" in this institutional culture'?

It was in this context that we asked a set of participants who self-identified as lesbian, gay or bisexual (LGB) ${ }^{1}$ if they felt 'at home' in residence life on their university campus.

\section{THE STUDY}

The study site was a largely residential South African campus where some 45 per cent of the student body (70 per cent of first years and 57 per cent of all undergraduates) reside in the university's residence system for at least part of their degree period. Initial communication with potential participants was made through an email that was sent to an organisation that represents LGBTI students. It outlined the purpose and nature of the study and requested that it be shared with members so that those who were willing to participate in the study could contact the researchers. This mechanism yielded ten participants. The remaining participants were recruited using the technique of snowball sampling in which further participants are obtained by asking existing participants for referrals to others (Petersen and Valdez 2005, 154). As Biernacki and Waldorf $(1981,141)$ argue, this method is well suited for research of a personal nature which requires the knowledge of insiders to locate participants for study. In this way, a further four participants were recruited.

We were mindful of the drawback of snowballing as a method of recruiting participants, namely the possibility that the sample will become very uniform because it was drawn from one particular circle. Therefore, we deliberately attempted to ensure as much diversity in the sample of participants as possible while remaining within the main criteria for inclusion, which were the declared sexuality of the person and their having personal experience of residence life at the institution. Participants were at different stages of their education, ranging from first year to fifth with six being first year students, two in their second year, three third year students, two 
in their fourth year of study and one student in the fifth year of study. The sample included eight women and six men and three white participants and eleven black participants. Three of the participants identified as bisexual. The number of interviews conducted was determined by the principle of 'saturation' - the point at which initial analysis reveals that no new themes are emergent (Bowen 2008, 140), suggesting that the addition of further participants is unlikely to yield significant new insights for the purpose of the study.

Data were gathered in the form of narrative interviews. Kenneth Plummer argues that stories, while told by individuals, embody social worlds (Plummer 1995, 16-17; also see Bamberg 2006, 145; Bell 2002; Herman and Vervaeck 2001, 1). As Richardson (1990 in Özyıldırım 2009, 1220) points out, telling stories about ourselves is the primary way in which human beings make meaning of the events in their lives and organise their experiences. Narrative interviewing stimulates the interviewee to tell a story (or stories) of significant events placed in a particular context. Thus, a research process which deliberately elicits the stories of participants, inviting them to frame their responses in a narrative form, is able to provide the researcher with an insight into this process of meaning making which would be impossible were the research to be restricted to say, close-ended questionnaire or survey responses.

Participants were prompted to tell stories about their understandings of feeling 'at home' and what the idea of home meant to them as well as stories which would provide an insight into what it feels like to live in residence with a preponderance of heterosexual peers in an environment that might be described as heteronormative. The duration of the interviews ranged from a minimum of one hour to a maximum of an hour and a half. Participants were presented with an opportunity to take a leading role in the interviewing process while they shared their stories and the lead author took on the role of an active and attentive listener, who allowed participants to elaborate on their experiences as far as possible without her intervention (Fossey et al. 2002, 727; Jovchelovitch and Bauer 2000). Interviews were conducted in spaces where participants felt comfortable including coffee shops, the botanical gardens, and participants' university residence rooms.

Permission to record the interviews was obtained and written informed consent was elicited from all the participants who signed consent forms which clearly outlined the purpose of the study and the procedures that would be undertaken for the protection of the anonymity of participants including the use of pseudonyms and an assurance of confidentiality whereby the original data would be securely stored and the identity of the participants not disclosed to anyone. Participants were afforded the right to withdraw their consent to participation at any stage. 
The resultant transcribed narratives were analysed using the techniques of narrative analysis. The narratives were treated as forms of discourse whose purpose was to arrange events in the teller's life (see Elliot 2005). Drawing on the work of scholars of narrative research such as Gareth Williams (1984) and Janice Goodman (2004), analysis took the form of a theoretically-directed thematic analysis. That is to say themes that were emergent or preponderant in the data were articulated in the analysis using as a lens the central concepts distilled from the theoretical literature stipulating the characteristics of home and at-homeness (Porteous 1976; Hayward 1977; Dovey 1985; Sixsmith 1986; Smith 1994; Mallet 2004; Thaver 2006; Moore 2007; Jacobson 2009).

Coding was facilitated by the use of NVivo software to store, organise, manage and make sense of the data. Initial coding generated 113 codes which were reduced during a second coding cycle in which the most frequent and significant codes were identified in order to inform the major categories of analysis that would be used to report the findings, namely home as a place for the development of a sense of identity, home as a place of comfort/discomfort, as well as questions of privacy, belonging, security, recognition and social relations.

\section{FINDINGS}

\section{Home as a place where you can be yourself and grow}

Some participants experienced being able to express themselves for the first time at university and reported feeling 'free’ to exhibit their sexual identity in residence life. They experienced a sense of community and were able to feel 'at home' because they encountered open-minded attitudes towards being gay on the part of other members of the residence. Siyabonga, for example, spoke of university as a 'home' which had allowed him to grow because, 'it allows you to establish your own values, it allows you to know yourself because it allows you to experience life'.

To feel that one will not be rejected because of one's identity is a critical feature of being able to experience an environment as homely and is particularly critical for individuals who are at a stage in their lives when they are growing into an adult identity (Dietz and Dettlaff 1997). Josh for example, talks of experiencing university as a place to 'be who you are' and where he could 'do so much more' than was possible in his (real) home in a small conservative town.

Actually, [this university] is the first time I've managed to meet other people who identify as gay and lesbian because I'm from a very conservative small town. You can do so much more here than you can do at home. You can be who you are at [this university]. I mean there is less restriction on how you can behave. People are very supportive here and it's not hard to find people with 
similar interests. There's a greater sense of community here ... I feel like there is more freedom to express yourself here than there is at home. (Josh).

Josh's narrative speaks to some of the most essential qualities of home: a support structure, a sense of community life, and 'freedom', which, all contribute to a sense of being 'at home'. The latter is experienced particularly starkly by those whose prior 'home' lives were infused with hostility and restrictions on the performance of their identity.

I come from a family where I have always been told that it's wrong [being gay], it's dirty. I have been told that if you are gay you are a soiled person, you are a soulless person and less of a person just because you like someone of the same sex. My dad always drilled that into my head that being homosexual is wrong. My cousin's dad just tells my cousin [because she is lesbian] that she is the scum of the earth because of her sexual orientation. (Thato).

Evans $(2000,84)$ finds that since a university is often a place where individuals experience their first intimate relationships, for LGBT students an environment of security and acceptance makes tertiary education institutions crucial sites for being able to come to terms with their sexual orientation for the first time. In the South African social context, characterised by high levels of homophobia in many communities (Nel and Judge 2008; Gontek 2009; Vincent and Howell 2014), the home environment that students leave when coming to university have often not been places where they have been able to feel 'at home' with their gay identity.

When gay students feel 'at home' at university, campus can become a place for growth, identity formation and positive social relations. But when those conditions are absent social ostracism is an ever-present fear, and home becomes a battleground, as Olwetu describes:

I hate having to wake up every morning and feel like I'm fighting a battle. Every day I ask myself if I'm dressed too gay or not or if my haircut is too boyish or if I should get offended every time someone makes a mistake that I'm a boy. This can't be my life. I should be stressing about something else like being broke like other students and not about my identity. (Olwetu).

While being comfortable to be yourself 'at home' requires a sense of ease and being able to socialise with friends and engage in a more intimate level of relationships and exchanges. Thato refers to the dilemmas attached to the expression of one's sexual identity when that identity is not heterosexual.

I may be able to hold a girl's hand in public but if I'm sober to kiss her? It's unimaginable. I don't know why I would feel uncomfortable with that. Especially in res, I don't think I could walk in the corridor and make out with my girlfriend or hold her hand. It's not an outward thing; they don't plan the system that way. It's not like someone is watching you and saying don't do that but it just doesn't feel right. (Thato).

While a young heterosexual couple 'making out' in the residence corridor would attract few 
comments, when the intimacy is between two members of the same sex it is amplified and noticed so that it 'just doesn't feel right'. Thato's important insight demonstrates how heteronormativity reproduces itself, not by decree or design or explicit rules, but through the internalisation of anticipated disapproval which acts as a powerful mechanism to produce the same disciplinary effect as explicit prohibition.

Scholars such as D’Augelli, (1991; 1992, 383), Dugan and Yurman, (2011) and Ellis (2008) have argued that it is common for adolescents to actively seek out opportunities to explore their sexuality upon arrival at university, away from the scrutiny of childhood friends and relatives. For those who inhabit home spaces that are inhospitable to their sexuality, going to university represents the hope of finding a new kind of space where the expression and further development of an identity that is stigmatised 'at home', might become possible. This hope is not always fulfilled. Tom for example spoke of his disappointment at not feeling able to 'grow as a gay guy’ at university:

Since I've been here it's been difficult to find that gay culture that has really allowed me to start exploring in a tangible way what it means to be gay - and I don't mean having sex. I just mean interactions with other gays. I haven't had enough of that. It is a source of insecurity and discomfort for me 'cause I never really got any of that when I was at home because of the nature of my hometown and I'm coming here and in a way I feel like I'm not growing as a gay guy because it's almost a stifling environment right now. It's very disappointing for me. (Tom).

\section{Home as a place of security and freedom}

Essential to being able to feel comfortable is being able to feel secure. For many people, the idea of security is the most immediate connotation that they have with 'home'. As much as security inheres at the level of personal identity and social relationships, it is also very much related to the physicality and materiality of home. The geographic location of an institution for instance has been pointed out as one of the most crucial factors individuals take into consideration when choosing a university (Lukwaro 2013; Kane 2013). Geographic location is of particular importance for students who welcome a sense of distance and being removed from their families and previous home contexts. The inaccessibility of the university offers a welcome respite from the scrutiny of those family members and friends who might not approve of their sexuality. Lungile for instance described experiencing the university's isolated setting as 'like being on an island away from everything'.

I don't think that there is a university in South Africa that can afford homosexual students with an opportunity to be themselves like [this one] does. The fact that [we are isolated] is a good thing because no one just comes [here] and that's what's nice about it. No one can just come [here] and be like hey I was just passing by ... it's like you are on this island away from everything and you're just meeting these awesome people. (Lungile). 
Several participants pointed to the fact that the idea of 'home' connotes a sense of security which in turn is essential to an individual's growth in contrast to the stunting, stifling effect of having to continually hide one's identity. Megan, for instance, spoke of the discomfort of her homophobic (prior) home environment in contrast to feeling 'more comfortable' at university.

I feel more comfortable here because I'm not out to my father because he is very homophobic and racist and that's uncomfortable for me. It's ironic because he has a bisexual daughter. (Megan).

Similarly, Lungile and Thato:

[This university] is one of those places where you grow. The independence gives you [enough space to grow] because it's considered to be a liberal university. If I have kids one day, I will send them here because I know that once they come here they will come out knowing themselves. (Lungile).

It's a good res ...This res particularly is very ... I feel at home. I feel comfortable. (Thato).

For some participants though, this sense of security was markedly absent resulting in an attitude of tentativeness and carefulness which is the antithesis of what is commonly associated with feeling secure and 'at home'. Heather illustrates this point in the following way:

[I have noticed that even here on campus] there isn't a very high tolerance for homosexuality, so it's either you make up your mind to either date people of the opposite sex or [face the consequences of being gay]. (Heather).

D’Emilio $(1990,18)$ argues that residences are one of the prime places on university campuses where gay and lesbian students experience harassment, discrimination and even physical violence. This was the experience of participants like Kirsty who described residence as a hostile environment in which she felt uncomfortable, a 'place to live' rather than a 'home':

I will say, I know it's supposed to be a home on paper, but it's not really. It is a place to live for all but I wouldn't say it's a home for all. I did feel uncomfortable especially in one of the residences I lived in because for me it was a hostile environment. There was a lot of hostility expressed towards me by the other students and there were a lot of judgements directed towards me .... It was just certain people looking at you in a certain way. (Kirsty).

Valentine (1995) argues that gay and lesbian individuals develop a sense of 'sexual geography' whereby they may consider migration as an option in order to find 'safe zones' where they can find security to perform their identity. Mandla's experience of feeling the need to 'move residences' suggests that rather than being able to generalise across an institution to describe prevalent social relations as entirely homophobic or entirely welcoming to LGB members, campuses are comprised of multiple cultures, some more welcoming than others and that 
individuals learn to orient themselves in physical spaces in order to minimise their discomfort as far as possible.

This year I come back to the same res but I was just fed up to the point where I actually decided to move residences. I moved into a new place which is not the same as my old res but even worse than the other res. ...When I walk into the dining hall it's so awkward because no one wants to sit next to me at the dining table but I really don't care. All I do is put my headset on and I eat my food then leave. This is what I do every day. But even if someone ends up sitting with me it will be a matter of just greeting each other, no conversation. When I try to initiate a conversation, I can really sense that the other person doesn't want to talk to me so I just leave them alone. That's why I never make the mistake of leaving my headset behind when I go to the dining hall. (Mandla).

\section{Home is the place where you 'belong' and are accepted}

Smith $(1994,32)$ argues that having a place where one feels a sense of belonging engenders feelings of continuity, stability and permanence which we would typically associate with feeling 'at home'. Family homes are typically situated in communities where a sense of belonging contributes to a positive sense of 'home life'. When individuals perceive that they have social support, their mental and physical health is maintained (Walton and Cohen 2007, 82). Mpho recalled her experience of coming to university:

My home background wasn't as open as here so I wasn't really sure about my sexuality and all the issues related to that. Then I came to this university and you know it was just something that people did. People were just hooking up and sleeping over you know. So, it became easier to be myself here. It's been great for me here. I had my first real girlfriend here. I fell in love and it was beautiful. (Mpho).

Similarly, for Anele, to be 'at home' was to experience the university as a place of 'openness' and being able to 'be myself'.

Well ever since I got here I must say the sense of openness in this place is great. It's much easier for me to be myself .... Coming to study here did open up opportunities for me to be myself. (Anele).

We played a lot of games in res in order to get to know each other and in one game we had to tell two lies and one truth about ourselves and I said, 'I'm left-handed, anti-Christ and I'm bisexual, which one is a lie?' And everybody guessed right. Even after they found out that I'm bisexual nobody really cared and it was just one of those things. (Heather).

Several participants contrasted the feeling of belonging in their university residence with the absence of that feeling in their previous home environments where they had felt like they did not belong.

It's much more open-minded here. Like I know at home in my neighbourhood, I couldn't just be openly bisexual because I'm not out to my friends at home because I know that they are still a bit touchy about it .... (Megan). 
Students here tend to be more open-minded, more liberal leaning so there is room to be more open about who you are here. I mean you are free to express yourself in ways I could definitely not do back home in Port Elizabeth. (Josh).

But not all the participants had experienced belonging in university residence life. If the idea of 'home' connotes acceptance, the contrast is to find oneself 'judged' as Lebo explains:

Everything is a little bit different in res. I have friends who are conservative .... I've kinda found it hard to talk to my conservative friends about what I feel and my sexuality and everything related to that. [For example] if I meet someone I can't say I met this girl 'cause I start to think about what they will say. Whether they will judge me or not. I would like my res to just make me feel a little bit more at home you know. People don't realise that there might be people struggling with their identities but can't talk to anybody in the res because people are just shying away from having discussions. It's all about just feeling welcomed because it is tough being gay. Like just dealing with that - thinking that you're this outcast, you just need somebody who understands what you're going through and I have none of that. Here it's just like this one-man mission where I'm just like Lebo you can do this; just self-motivation that you can do it, you can do this .... (Lebo).

Lebo invoked the idea of home connoting filial bonds which are often explicitly appealed to in university residence environments where those in leadership positions attempt to create a sense of belonging but which can serve to be exclusionary. When a sense, for example, of 'sisterhood' is created among residence members this very act of creating belonging through shared experiences can serve to exclude those who do not share these experiences. Lebo referred to how 'they always say we are sisters at this res' but went on to comment that 'as sisters we don't do any of these things that makes us sisters'. Shared confidences about relationships become a source of belonging for some while at the same time isolating others.

What Walton and Cohen $(2007,82)$ term 'belonging uncertainty' arises because members of stigmatised groups in academic settings are uncertain about the quality of their social bonds and hence experience belonging uncertainty. Belonging uncertainty may lead to individuals feeling that 'people like me do not belong here' (Walton and Cohen 2007, 83).

The first term I didn't pay much attention to it and the second term I was getting a little bit of a vibe here that these people are not too accepting and I think as the months have gone by, I've seen it more. I'm seeing it more now it's [homosexuality] just not something that they are willing to accept. (Lebo).

Mpho described her insecurity about her sexuality which is reinforced by her sense that her otherness leads to discomfort on the part of others. Knowing that home is a place where people ought to be able to feel at ease in private spaces such as the bathroom, she fears that her presence will occasion discomfort for others and this in turn heightens her own sense of non-belonging.

Well I will say personally when I got here, I was still not comfortable with my sexuality and 
therefore everything that I saw happening because of my own insecurity around my sexual orientation, I felt like people were just discriminating against me. For example, I was acutely aware even without saying it that I was a lesbian but then when I went to the showers I was like oh my goodness they know and do they think I will be checking them out. Am I making them uncomfortable by being here and [I was] always worried about what they thought. And in actual fact it just doesn't work that way. You are not just attracted to all women. I was worried that they thought that just because they are women and I like women then I would like them, that I would look at them inappropriately if they were naked you know. (Mpho).

While expressing a yearning to belong, participants described at times excluding themselves from social interactions in order to minimise their discomfort. Denied a sense of belonging, Musa chooses 'keeping to himself' as a mechanism to protect himself.

[I hope] eventually people will get to a point where they are fine with homosexuals but then not everyone is there yet. And when somebody tells you they are fine with it and then you act as the person that you are they pull back. If somebody tells you look I'm not [comfortable with you being gay] you will respect their space. It's like somebody who is pregnant you can say to them I'm fine with it but then when they start talking about their pregnancy and making jokes about it you pull back. The problem is that people act as if they are fine with homosexuality but then they are not. The only reason why I'm comfortable here is because I keep to myself. I'm naturally someone who keeps to myself but I'm more so because of the environment that I live in. If I was living in an environment where homosexuality is highly acceptable, where even the most Christian of people accept you as you are I would have been more outgoing and not keeping to myself .... (Musa).

\section{Home is associated with community and support}

Some participants, like Megan, invoked the idea of good neighbourliness and community as characterising their experience of residence life.

It kinda feels like I live with my family. It's like when I run out of milk, I can knock on someone else's door and say dude can I please have some milk I've run out. You form relationships and you're able to talk about anything that's bothering you. Your neighbours can just knock on your door to tell you what happened to them. So yeah there is actually a sense of feeling at home. (Megan).

Similarly, Siyabonga experiences a sense of 'community' in his university residence because it is a place where people care about his well-being:

I think in my res, there's a sense of community. I think I'm very lucky in that way, my res is not particularly like other residences. I am in a lucky situation because people go to the extent of inquiring about people in my life. They are concerned about your well-being and I think I'm just lucky to be living with people like that. (Siyabonga).

But some participants reported that it was difficult to feel supported because, as Thato explained, to ask for support may mean to confide in people about one’s sexual identity which has consequences for being able to 'fit in' when that identity is gay: 
I think with res it's not issues with the res. It's society and the way it handles homosexuals or people with different sexual orientations. And it's usually just the fact that we always have to be careful who we tell because it changes how people will view you no matter how open minded they may be .... For the first couple of months I couldn't get myself to be okay with being who I was in this space. And it's not because there aren't measures in place or anything like that, it's just difficult especially in first year. Trying to fit in and those initial couple of weeks are very difficult to be bisexual or lesbian or gay. (Thato).

Far from looking forward to going 'home' to his residence, Mandla spends as little time as possible there because he is 'not comfortable'.

My coping mechanism is to actually not spend time in the res. I'm never there [in res]. It's because I'm not comfortable ... and the only way I can deal with all the stresses that I encounter in res is to wake up, shower and come to campus. Even when I do not have lectures I am on campus. The time that I'm supposed to be spending in my room I spend it on campus. I literally go to my res for lunch then come back down. I go to computer labs and go back when everyone is minding their own business in their rooms. That's my experience with res life. I think in the residences they still have a long way to go and I think it's also because the res is supposed to be home and if I am gay in my house I'm expecting that they are the first core of support more than anything. And if I don't get that, I mean it's not home it's just a place where I shower and sleep. (Mandla).

Rather than the residence being a home where one relaxes and socialises it becomes a place for performing basic functions such as sleeping, eating and showering which might be said to be associated with being 'in' a home rather than 'at' home. For Josh, continually being in the position of occupying the minority position is trying.

I mean nowadays I don't mean to hate on my friends but they are all straight so a lot of times it ends up me being the token gay guy which is kinda weird. (Josh).

Another participant, Tom, spoke powerfully of his isolation and how this had resulted in an internalised feeling of something being wrong with him. Without access to social sounding boards the social world becomes unintelligible to him and the interview provides a rare opportunity to 'talk about it'.

It may be that there is something wrong with me to make it possible for me to get into a gay culture and that's why I haven't found one. I just feel like there's something I'm doing wrong. Maybe I'm supposed to do something about my personality, or the way I act, or my body. I'm not exactly sure what it is most of the time. It's very difficult and complicated and actually just talking about this now I've learnt so much more than I thought I knew in the first place because for the most part not speaking about it and having all this in my head makes it all confusing. I don't know how I'm feeling most of the time because there are so many social nuances at play and I don't know where the web is connecting. (Tom).

Sexual minorities living in communities that are highly heterosexual in nature experience isolation and an exaggerated sense of being different (Dietz and Dettlaf 1997, 60). Isolation 
from supportive peers can hinder the development of a person's identity and cause significant stress. Scholars such as D’Augelli (1993) have argued that this means that young adults who identify as gay or lesbian experience stress in the management of their sexual orientation. Swank and Raiz (2010, 26-27) point out that as a result of living in heterosexist homes and communities where there is a perpetuation of stereotypes and negative perceptions about homosexuality, by the time gay and lesbian youths arrive at university they have internalised homophobia and blame themselves, as Tom does, for their isolation. Some find themselves having to make difficult decisions about when and whether it is appropriate to express themselves and under which circumstances it is acceptable to perform their identity as Mpho explains:

The res itself was never an issue. Of course, the issues were with me. But not external. It was always an internal questioning: should I bring a girl over? If I bring a girl over will they know? And if they know will that change anything? It was all about how I thought they would react. So, the interrogation was never external it was always internal but I never had a breakdown. (Mpho).

The social relations that prevail in the home, as Gareth Williams $(1984,187)$ argues, play a central role in how a sense of identity is developed or constrained, nurtured or broken down. It is in the home that one either develops a sense of who one is by having the freedom to express oneself or experiences suppression and denial of the opportunity to perform one's identity as desired. It is through interaction with others in the home that individuals are able either to confidently express themselves or struggle to establish a concrete sense of who they are. Dating is a prominent example of how residence life can be an impediment to self-expression for gay and lesbian students. Some participants expressed high levels of anxiety - even 'shit your pants fear' - occasioned by the risk of exposure.

It's a fear. It's an innate fear that you will be judged and you will be treated differently and we really just want to be loved for who we are. And it is what it is. Literally shit your pants kinda fear. (Thato).

Leary $(2006,2)$ argues that human beings have a strong need to belong and are wary of rejection and a lack of acceptance from others. Human beings value the establishment and maintenance of positive interpersonal relations with others and failure to have such relations can be distressing for those who are rejected (Leary 2006, 2). It is often 'at home' that one has an expectation of experiencing belonging, acceptance and, as Thato puts it a lack of 'judgement' but these are the features that might precisely be lacking for the person who is gay in residence.

I think in truth, just like everyone else we don't want to be judged. We want to be accepted for who we are. I don't know how to explain it ... it's just extremely difficult because you kinda start 
off on a disadvantage in terms of reputation. I would like people to realise that we are not saddened by the fact that we are different. It's not something that we are ashamed of. I mean ... we get to a place where now we realise that it's who we are. We also don't want people to feel sorry for us. I just wish people would realise that what we need is someone to understand ... to just try to understand. I just want you to want to understand us instead of just being afraid of us or being uncomfortable around us ... And I think people have to realise we have dreams, we have aspirations and we have places to go and people to see. You come to a point where you can't now stop and die every time that someone does something weird or says something ... we're just trying to live our lives. (Thato).

\section{People recognise you at home}

To be 'at home' is to experience a certain freedom to be oneself, to be unguarded and open, which arises when there are others who are 'alike' and who are able to recognise who we are. Kirsty for instance associates 'liberty' with finding gay friends and a gay culture for the first time:

I had never really been in a relationship before coming to university and I wanted to see what the culture was like because at home I didn't have any gay friends. I didn't have a gay culture at home and I never really experienced any sort of liberty there you know. And when I came here I wanted to try being in a relationship, to express myself because most people find their identities at university and that's what happened with me. (Kirsty).

Taylor (1994, 25) argues that peoples' identities are partially shaped by recognition or misrecognition on the part of those who surround them. For Taylor $(1994,26)$, recognition is not merely a courtesy but a human need. Beverley Skeggs $(2001,296)$ argues that 'to make a recognition is to participate in a system of judgment and classification'. Some participants reported experiencing social relations in the residence environment as unaccommodating and hostile when they perceive their heterosexual peers to lack understanding or to 'misrecognise' what it means to be gay.

I think a lot of people think I hate men. I don't hate men but most of them really annoy me and as soon as I say men annoy me [they all say] yeah it's 'cause you're gay', [and I try to explain] that that's not how it is and they won't even give me a chance to explain, it's just an immediate attack: No Lebo you're gay - just because you're gay doesn't mean all men are bad. They tell me that I haven't been in a heterosexual relationship so I don't know any better. I just wished they understood that I don't hate men. (Lebo).

Fraser (1995, 77-78) argues that to be misrecognised is not only to be devalued but to be denied the right to be a full partner in social interaction and gay and lesbian individuals constantly experience this denial. Tully $(2000,470)$ argues that misrecognition undermines the basic selfrespect and self-esteem that is necessary to empower individuals to develop a sense of autonomy and self-worth which is needed to participate in public and private life. As Taylor $(1994,25)$ points out, an individual or a group of people can suffer real damage if the people 
around them mirror back to them a confining or demeaning picture of themselves. Misrecognition can inflict harm on those who experience it and it can be a form of oppression that imprisons individuals in a false, distorted and reduced mode of being (see also Chariandy 2005, 147).

\section{CONCLUSION}

The worth of in-depth interviews with a small number of participants lies of course not in their representivity but rather in their ability to reveal valuable insights into the texture of lived experience as individuals try to make sense of their lives within a particular social context. Seeing our institutions through the lens of the experiences of the most vulnerable and marginalised has the potential to act as barometer of transformation. By foregrounding the experiences of those who do not occupy the position of the dominant norm, we are able to be alerted to ways in which our presuppositions and practices might perpetuate relations of dominance and subordination and may not be as incorporative as we would hope them to be. On the other hand, to the extent that the experiences of the vulnerable and marginalised reflect positively on existing practices and social relations, this can be taken as an indication that policies embracing diversity and equality are being put into practice effectively.

The findings reported here show that there is no singular residence culture that can be pointed to at the study site but rather, that the participants' experiences of residence life are mixed. Some report experiences of comfort, security and the freedom to be themselves for the first time in their lives, while others experience discomfort, alienation, ostracism and nonbelonging. For some, transitioning to university is experienced as finding the essential qualities of home, such as freedom, comfort, belonging, acceptance and companionship which in some cases had been absent in their family and community homes. These participants' stories demonstrated how significant it is for them to live in environments where they can feel 'at home'. Not all the participants had experienced residence life as a place of personal growth, identity formation and flourishing relationships. Campuses can be difficult environments for students who do not identify as heterosexual and who may be misrecognised, judged and ostracised by their peers.

The stories told here offer a perspective that interrupts the dominant, taken-for-granted, heterosexual experience of institutional life, and show how while formal policies provide a framework within which social relations play themselves out, we need to do more than merely legislate non-discrimination. By foregrounding the experiences of those who do not occupy the position of the dominant norm we are able to be alerted to ways in which our presuppositions 
and practices might perpetuate relations of dominance and subordination and may not be as incorporative as we would hope them to be.

When university residences are places where students find acceptance for who they are, they can play a significant role in fostering the wellbeing of individuals, fulfilling the fundamental human need for recognition, acceptance and welcoming on the part of others. The social relations that are established and maintained in the residence context between LGBTI students and their heterosexual peers either produce a sense of belonging and comfort or of exclusion, discomfort, and ostracism - being ignored, judged or excluded by those whose subject positions represent dominant orthodoxies. When students, who find themselves in a minority because of their sexual preference, encounter acceptance, understanding and an environment that normalises rather than exceptionalises their identity, they are able to flourish and be happy - they feel, 'at home'.

\section{NOTE}

1. While the experiences of intersexed and transgendered students would provide valuable insights into how residential cultures need to be transformed further, no participants in the present study identified as intersexed or transgendered. We therefore restrict our observations to LGB rather than LGBTI so as not to presume to speak for those whose own voices did not emerge in the research process.

\section{REFERENCES}

Arndt, M. 2004. Attitudes towards lesbian and gay men: A university survey. Master's dissertation. University of Johannesburg, Johannesburg.

Arndt, M. and G. de Bruin. 2006. Attitudes toward lesbians and gay men: Relations with gender, race and religion among university students. Psychology in Society 33: 16-30.

Bamberg, M. 2006. Stories: Big or small. Why do we care? Narrative Inquiry 16(1): 139-147.

Beemyn, G. and S. Rankin. 2011. Introduction to the Special Issue on 'LGBTQ Campus Experiences'. Journal of Homosexuality 58(9): 1159-1164. DOI:10.1080/00918369.2011.605728.

Bell, J. S. 2002. Narrative inquiry: More than just telling stories. TESOL Quarterly 36(2): 207-213.

Biernacki, P. and D. Waldorf. 1981. Snowball sampling. Problems and techniques of Chain Referral Sampling. Sociological Methods and Research 10(2): 141-163.

Bowen, G. A. 2008. Naturalistic inquiry and the saturation concept: a research note. Qualitative Research 8(1): 137-152.

Bowlby, S., S. Gregory and L. McKie. 1997. 'Doing home': Patriarchy, caring and space. Women’s Studies International Forum 20(3): 343-350.

Chariandy, D. 2005. 'That's what you want, isn't it?': Austin Clarke and the New Politics of Recognition. Journal of West Indian Literature14(1/2): 141-165.

D’Augelli. A. R. 1989. Lesbians and gay men on campus: Visibility, empowerment, and educational leadership. Peabody Journal of Education 66(3): 124-142.

D’Augelli. A. R. 1991. Gay men in college: Identity processes and adaptations. Journal of College Student Development 32: 140-146.

D’Augelli, A. R. 1992. Lesbian and gay male undergraduates' experiences of harassment and fear on 
campus. Journal of Interpersonal Violence 7(3): 383-395.

D'Augelli, A. R. 1993. Preventing mental health problems among lesbian and gay college students. The Journal of Primary Prevention 13(4): 245-261.

D’Emilio, J. 1990. The campus environment for gay and lesbian life. Academe 76(1): 16-19.

Department of Education. 1997. White Paper 3: A Programme for the Transformation of Higher Education. Pretoria: DoE.

Department of Education. 2008. Report of the Ministerial Committee on Transformation and Social Cohesion and the Elimination of Discrimination in Public Higher Education Institutions. Final Report. Pretoria: DoE.

Dietz, T. J. and A. Dettlaff. 1997. The impact of membership in a support group for gay, lesbian, and bisexual students. Journal of College Student Psychotherapy 12: 57-72. DOI: 10.1300/J035v12n01_06.

Donaldson, N. 2015. What about the queers? The Institutional Culture of Heteronormativity and Its Implications for Queer Staff and Students. In Being at home. Race, institutional culture and transformation at South African Higher education institutions, ed. P. Tabensky and S. Matthews, 130-146. Pietermaritzburg: University of Kwa Zulu-Natal Press.

Dovey, K. 1985. Home and homelessness. In Home environments, ed. I. Altman and C. M. Werner, 3364. New York: Plenum Press.

Dugan. J. P. and L. Yurman. 2011. Commonalities and differences among lesbian, gay, and bisexual college students: Considerations for research and practice. Journal of College Student Development 52(2): 201-216.

Easthope, H. 2004. A place called home. Housing, Theory and Society 21: 128-138. DOI: 10.1080/14036090410021360.

Elliot, J. 2005. Using narrative in social research. Qualitative and quantitative approaches. London: Sage Publications.

Ellis, S. J. 2008. Diversity and inclusivity at university: A survey of the experiences of lesbian, gay, bisexual and trans (LGBT) students in the UK. Sheffield: Sheffield Hallam University Research Archive: 1-32.

Engstrom, C. and W. Sedlacek. 1997. Attitudes of heterosexual students towards their gay male and lesbian peers. Journal of College Student Development 38(6): 565-576.

Evans, N. J. 2000. Creating a positive learning environment for gay, lesbian, and bisexual students. New Directions for Teaching and Learning 82: 81-87.

Evans, N. J. and A. D'Augelli. 1996. Lesbians, gay men and bisexual people in college. In The lives of lesbians, gays, and bisexuals. Children to adults, ed. R. C. Savin-Williams and K. M. Cohen, 201226. Florida: Harcourt Brace \& Company.

Fossey, E., C. Harvey, F. McDermott and L. Davidson. 2002. Understanding and evaluating qualitative research. Australian and New Zealand Journal of Psychiatry 36(6): 717-732.

Francis, D. and T. Msibi. 2011. Teaching about heterosexism: Challenging homophobia in South Africa. Journal of LGBT Youth 8: 157-173. DOI:10.1080/19361653.2011.553713.

Fraser, N. 1995. From redistribution to recognition? Dilemmas of justice in a 'post-socialist' age. New Left Review I(212): 68-94.

George, R. M. 1996. The politics of home. San Diego: University of California Press.

Gontek, I. 2009. Sexual violence against lesbian women in South Africa. International Resource Network Outliers, a Collection of Essays and Creative Writing on Sexuality in Africa 2: 1-18.

Goodman, J. H. 2004. Coping with trauma and hardship among unaccompanied refugee youths from Sudan. Qualitative Health Research 14: 1177-1196.

Govinder, K. S., N. P. Zondo and M. W. Makgoba. 2013. A new look at demographic transformation for universities in South Africa. South African Journal of Science 109(11/12): 1-11. 
Hauge, A. L. 2007. Identity and place: A critical comparison of three identity theories. Architectural Science Review 50(1): 44-51.

Hayward, D. G. 1977. Housing research and the concept of home. Housing Educators Journal 4(3): 712.

Herman, L. and B. Vervaeck. 2001. Handbook of narrative analysis. Lincoln and London: University of Nebraska Press.

Jacobson, K. 2009. A developed nature: A phenomenological account of the experience of home. Continental Philosophy Review 42: 355-373.

Jenkins, M., E. G. Lambert and D. N. Baker. 2009. The attitudes of black and white college students toward gays and lesbians. Journal of Black Studies 39: 589-613.

Jovchelovitch, S. and M. W. Bauer. 2000. Narrative interviewing [online]. London: LSE Research Online. http://eprints.lse.ac.uk/2633 (accessed 15 March 2015).

Kane, M. D. 2013. Finding 'safe' campuses: Predicting the presence of LGBT student groups at North Carolina colleges and universities. Journal of Homosexuality 60(6): 828-852. DOI: 10.1080/00918369.2013.774837.

Kaplan, C. 1987. Deterritorialisations: The rewriting of home and exile in Western feminist discourse. Cultural Critique 6: 187-198.

Leary, M. R. 2006. Towards a conceptualization of interpersonal rejection. In Interpersonal rejection, ed. M. R. Leary. Published to Oxford Scholarship Online: March 2012. http://0www.oxfordscholarship.com.wam.seals.ac.za/view/10.1093/acprof:oso/9780195130157.001.000 1/acprof-9780195130157 (accessed 17 March 2015).

Lukwaro, G. 2013. Is location important when selecting a university? American University of Sharjah Blog Post. http://blog.aus.edu/bid/259261/Is-location-important-when-selecting-a-university (accessed 19 March 2015).

Mallet, S. 2004. Understanding home. The Sociological Review, 62-89.

Manzo, L. C. 2003. Beyond house and haven: Toward a revisioning of emotional relationships with places. Journal of Environmental Psychology 23: 47-61.

Moore, J. 2007. Polarity or integration? Towards a fuller understanding of home and homelessness. Journal of Architectural and Planning Research 24(2): 143-159.

Msibi, T. 2013. Queering the transformation of higher education in South Africa. Perspectives in Education 31(2): 65-73.

Nel, J. A. and M. Judge. 2008. Exploring homophobic victimization in Gauteng, South Africa: Issues, Impacts and responses. Acta Criminologica 21(3): 19-36.

Nelson, R. and H. Baker. 1990. The educational climate for gay, lesbian and bisexual students. A paper presented at the Annual Conference of the Association for Institutional Research. Louisville, Kentucky.

Özyıldırım, I. 2009. Narrative analysis: An analysis of oral and written strategies in personal experience narratives. Journal of Pragmatics 41: 1209-1222.

Petersen, R. D. and A. Valdez. 2005. Using snowball-based methods in hidden populations to generate a randomized community sample of gang-affiliated adolescents, Youth Violence and Juvenile Justice 3(2): 151-167. DOI: 10.1177/1541204004273316.

Plummer, K. 1995. Telling sexual stories: Power, change and social worlds. London: Routledge.

Porteous, J. D. 1976. Home: The territorial core. Geographical Review 66(4): 383-390.

Reed, E., G. Prado, A. Matsumoto and H. Amaro. 2010. Alcohol and drug use and related consequences among gay, lesbian and bisexual college students: Role of experiencing violence, feeling safe on campus, and perceived stress. Addictive Behaviors 35: 168-171.

Rhoads, R. A. 1995. Learning from the coming-out experiences of college males. Journal of College Student Development 36(1): 67-74. 
Richardson, E. M. 2006. Researching LGB youth in post-apartheid South Africa. Journal of Gay and Lesbian Issues in Education 3(2/3): 135-140. DOI: 10.1300/J367v03n02_15.

Said, E. W. 1983. The world, the text and the critic. Cambridge, Mass: Harvard University Press.

Sixsmith, J. 1986. The meaning of home: An exploratory study of environmental experience. Journal of Environmental Psychology 6: 281-298.

Skeggs, B. 2001. The toilet paper: Femininity, class and mis-recognition. Women's Studies International Forum 24(3/4): 295-307.

Smith, S. G. 1994. The essential qualities of a home. Journal of Environmental Psychology 14: 31-46.

Soudien, C. 2010. Transformation in higher education: A briefing paper. Development Bank of Southern Africa: 1-29. http://www.dhet.gov.za/summit/Docs/2010Docs/Transformation\%20in\%20higher \%20education-\%20A\%20briefing\%20paper\%20by\%20Crain\%20Soudien.pdf (accessed 12 February 2015).

Swank, E. and L. Raiz. 2010. Attitudes toward gays and lesbians among undergraduate social work students. Affilia, Journal of Women and Social Work 25(1): 19-25 DOI: 10.1177/0886109909356058.

Taylor, C. 1994. The politics of recognition. http://chrr.info/files/1taylor_politics_of_recognition.pdf (accessed 21 March 2015).

Tetreault, P. A., R. Fette, P. C. Meidlinger and D. Hope. 2013. Perceptions of campus climate by sexual minorities. Journal of Homosexuality 60(7): 947-964. DOI:10.1080/00918369.2013.774874.

Thaver, L. 2006. 'At home', institutional culture and higher education: Some methodological considerations. Perspectives in Education 24(1): 15-26.

Tully, J. 2000. Struggles over recognition and distribution. Constellations 7(4): 469-482.

Valentine, G. 1995. Out and about: Geographies of lesbian landscapes. International Journal of Urban and Regional Research 19(1): 96-111.

Vice. S. 2015. Feeling at home: Institutional culture and the idea of a university. In Being at 'home': Race, institutional culture and transformation at South African higher education institutions, ed. P. A. Tabensky and S. Matthews, 45-71. Pietermaritzburg: University of KwaZulu-Natal Press.

Vincent, L. and S. Howell. 2014. 'Unnatural', 'Un-African' and 'Ungodly': Homophobic discourse in democratic South Africa. Sexualities 17(4): 472-483.

Waldo, C. R.1998.Out on campus: Sexual orientation and academic climate in a university context. American Journal of Community Psychology 26(5):745-774.

Walton, G. M. and G. L. Cohen. 2007. A question of belonging: Race, social fit, and achievement. Journal of Personality and Social Psychology 92(1): 82-96.

Wardhaugh, J. 1999. The unaccommodated woman: Home, homelessness and identity. Sociological Review 47(1): 91-109.

Westefeld, J. S., M. R. Maples, B. Buford and S. Taylor. 2001. Gay, lesbian, and bisexual college students. Journal of College Student Psychotherapy 15(3): 71-82.

Williams, G. 1984. The genesis of chronic illness: narrative re construction. Sociology of Health and Illness 6(2): 175-200.

Woodford, M. R., A. R. Krentzman and M. N. Gattis. 2012. Alcohol and drug use among sexual minority college students and their heterosexual counterparts: The effects of experiencing and witnessing incivility and hostility on campus. Substance Abuse and Rehabilitation 3: 11-23. http://socwork.wisc.edu/files/Alcohol-Drug-Use-Gattis.pdf (accessed 17 February 2015).

Yost, M. R. and S. Gilmore. 2011. Assessing LGBTQ campus climate and creating change. Journal of Homosexuality 58(9): 1330-1354. DOI:10.1080/00918369.2011.605744.

Younkins, E. W. 2008. Toward the development of a paradigm of human flourishing in a free society. The Journal of Ayn Rand Studies 9(2): 253-304. http://www.quebecoislibre.org/5-younkins.pdf (accessed 16 November 2016). 